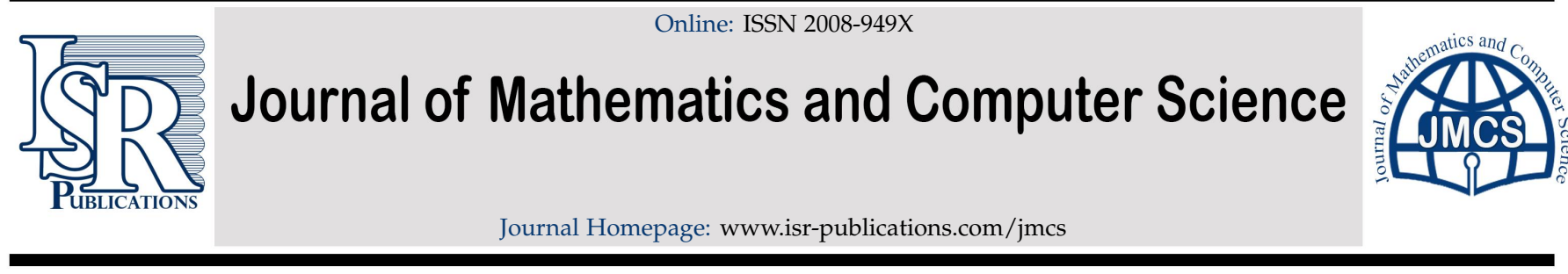

\title{
Laplace discrete decomposition method for solving nonlin- ear Volterra-Fredholm integro-differential equations
}

\author{
Lafta A. Dawood ${ }^{a}$, Ahmed A. Hamoud ${ }^{b, *}$, Nedal M. Mohammed ${ }^{c}$ \\ a Department of Mathematics, Thi Qar Directorates of Education, Ministry of Education, Iraq. \\ ${ }^{b}$ Department of Mathematics, Faculty of Education and Science, Taiz University, Taiz, Yemen. \\ ${ }^{c}$ Department of Computer Science, Faculty of Education and Science, Taiz University, Taiz, Yemen.
}

\begin{abstract}
In this article, a new modification of the Adomian Decomposition Method (ADM) that is called the Laplace Discrete Adomian Decomposition Method (LDADM) is applied to non-homogeneous nonlinear Volterra-Fredholm integro-differential equations. This method is based upon the Laplace Adomian decomposition method coupled with some quadrature rules of numerical integration. The performance of the proposed method is verified through absolute error measures between the approximated solutions and exact solutions. The series of experimental numerical results show that our proposed method performs in high accuracy and efficiency. The study highlights that the proposed method could be used to overcome the analytical approaches in solving nonlinear Volterra-Fredholm integro-differential equations.
\end{abstract}

Keywords: Volterra-Fredholm integro-differential equation, Adomian decomposition method, Laplace transform, absolute error, approximated solution.

2020 MSC: 45J05, 65N55, 44A10.

(C)2020 All rights reserved.

\section{Introduction}

The integro-differential equations have attracted much more interest of mathematicians and physicists which provides an efficiency for the description of many practical dynamical arising in engineering and scientific disciplines such as, physics, biology, electrochemistry, chemistry, economy, electromagnetic, control theory and viscoelasticity $[2,3,5,12,13,15,16,19,21-23]$. In recent years, many authors focus on the development of numerical and analytical techniques for fractional integro-differential equations.

The LADM is known for its rapid convergence in solution and also uses only little iteration as successfully applied in Kiymaz [30]. Furthermore, several modifications of the ADM and LADM methods can be seen in [6] with wide applications ranging from differential equations, partial differential equations, integral equations and integro-differential equations among others. It seems that the LADM method is

\footnotetext{
*Corresponding author

Email address: drahmedselwi985@gmail.com (Ahmed A. Hamoud)
}

doi: $10.22436 /$ jmcs.021.02.07

Received: 2020-02-09 Revised: 2020-02-28 Accepted: 2020-03-03 
always open for further modifications especially on discretizing the Adomian decomposition. In this paper, we aim at extending the Laplace Adomian decomposition method for finding the solution of nonlinear integro-differential equations by firstly discretizing the ADM, followed by coupling some numerical integration schemes or quadrature rules [17].

We can solve integro-differential equations with some basis functions by the Chebyshev collocation method [4], Galerkin methods [8], Runge-Kutta methods [9], Taylor collection method [28], rationalized Haar functions method [31], Galerkin methods with hybrid functions [32], and ADM [7, 17, 34]. In addition to these numerical methods, Khuri [29] used Laplace transform numerical scheme. Moreover, properties of the integro-differential equations have been studied by several authors $[1,10,11,14,17,18$, $20,24-27,33]$.

In this paper, we shall be concerned with the nonlinear Volterra-Fredholm integro-differential equations of the second kind of the form

$$
y^{\prime \prime}(x)=f(x)+\int_{a}^{x} \Psi_{1}(x, t)\left(\Delta_{1}(y(t))+\Theta_{1}(y(t))\right) d t+\int_{a}^{b} \Psi_{2}(x, t)\left(\Delta_{2}(y(t))+\Theta_{2}(y(t))\right) d t
$$

with the initial conditions

$$
y(0)=\alpha, y^{\prime}(0)=\beta, a \leqslant x \leqslant b .
$$

The main objective of the present paper is to study the behavior of the solution that can be formally determined by analytical approximated method as the LDADM.

\section{Description of the Method}

Some powerful method has been focusing on the development of more advanced and efficient methods for nonlinear Volterra-Fredholm integro-differential equations such as the $\operatorname{LDADM}[7,17,34]$. We will describe this method in this section.

\subsection{Laplace Discrete Adomian Decomposition Method (LDADM)}

To solve the nonlinear Volterra-Fredholm integro-differential Eqs. (1.1)-(1.2) we use the Laplace transform method, we recall the Laplace transform of the second derivative of $y(x)$, that is

$$
\mathcal{L}\left\{\mathrm{y}^{\prime \prime}(\mathrm{x})\right\}=\mathrm{s}^{2} \mathcal{L}\{\mathrm{y}(\mathrm{x})\}-\mathrm{sy}(0)-\mathrm{y}^{\prime}(0) .
$$

Thus on applying the Laplace transform to both sides of Eq. (1.1) we obtain

$$
\mathcal{L}\left\{y^{\prime \prime}(x)\right\}=\mathcal{L}\left\{f(x)+\int_{a}^{x} \Psi_{1}(x, t)\left(\Delta_{1}(y(t))+\Theta_{1}(y(t))\right) d t+\int_{a}^{b} \Psi_{2}(x, t)\left(\Delta_{2}(y(t))+\Theta_{2}(y(t))\right) d t\right\} .
$$

From (2.1)

$$
\begin{aligned}
s^{2} \mathcal{L}\{y(x)\}-s y(0)-y^{\prime}(0)= & \mathcal{L}\{f(x)\}+\mathcal{L}\left\{\int_{a}^{x} \Psi_{1}(x, t)\left(\Delta_{1}(y(t))+\Theta_{1}(y(t))\right) d t\right. \\
& \left.+\int_{a}^{b} \Psi_{2}(x, t)\left(\Delta_{2}(y(t))+\Theta_{2}(y(t))\right) d t\right\}
\end{aligned}
$$

by using (1.2)

$$
\begin{aligned}
s^{2} \mathcal{L}\{y(x)\}-s \alpha-\beta= & \mathcal{L}\{f(x)\}+\mathcal{L}\left\{\int_{a}^{x} \Psi_{1}(x, t)\left(\Delta_{1}(y(t))+\Theta_{1}(y(t))\right) d t\right. \\
& \left.+\int_{a}^{b} \Psi_{2}(x, t)\left(\Delta_{2}(y(t))+\Theta_{2}(y(t))\right) d t\right\}
\end{aligned}
$$




$$
\begin{aligned}
\mathcal{L}\{y(x)\}= & \frac{\alpha}{s}+\frac{\beta}{s^{2}}+\frac{1}{s^{2}} \mathcal{L}\{f(x)\}+\frac{1}{s^{2}} \mathcal{L}\left\{\int_{a}^{x} \Psi_{1}(x, t)\left(\Delta_{1}(y(t))+\Theta_{1}(y(t))\right) d t\right. \\
& \left.+\int_{a}^{b} \Psi_{2}(x, t)\left(\Delta_{2}(y(t))+\Theta_{2}(y(t))\right) d t\right\} .
\end{aligned}
$$

The decomposition method represents the solution $y(x)$ as a series of the form

$$
y(x)=\sum_{n=0}^{\infty} y_{n}(x)
$$

and the nonlinear term $\Theta_{1}(y(t)), \Theta_{2}(y(t))$ are decomposed into an infinite series of the form

$$
\Theta_{1}(y(t))=\sum_{n=0}^{\infty} A_{n}, \quad \Theta_{2}(y(t))=\sum_{n=0}^{\infty} B_{n},
$$

where $A_{n}, B_{n}$ are the Adomian polynomials of $y_{1}, y_{2}, \cdots, y_{n}$, given by the formula

$$
A_{n}=\frac{1}{n !} \frac{d^{n}}{d \gamma^{n}}\left[\Theta_{1}\left(\sum_{i=0}^{n} \gamma^{i} y_{i}\right)\right]_{\gamma=0}, \quad B_{n}=\frac{1}{n !} \frac{d^{n}}{d \gamma^{n}}\left[\Theta_{2}\left(\sum_{i=0}^{n} \gamma^{i} y_{i}\right)\right]_{\gamma=0} .
$$

On substituting Eqs. (2.5)-(2.6) and (2.7) in Eq. (2.4) and making comparison between the right and left hand sides, we thus obtain:

$$
\begin{aligned}
\mathcal{L}\left\{y_{0}(x)\right\} & =\frac{\alpha}{s}+\frac{\beta}{s^{2}}+\frac{1}{s^{2}} \mathcal{L}\{f(x)\}, \\
\mathcal{L}\left\{y_{k+1}(x)\right\} & =\frac{1}{s^{2}} \mathcal{L}\left\{\int_{a}^{x} \Psi_{1}(x, t)\left(\Delta_{1}\left(y_{k}(t)\right)+A_{k}\right) d t+\int_{a}^{b} \Psi_{2}(x, t)\left(\Delta_{2}\left(y_{k}(t)\right)+B_{k}\right) d t\right\} .
\end{aligned}
$$

Finally, on applying the inverse Laplace transform to the first part of Eq. (2.8) $y_{0}(x)$ is given and consequently $A_{0}$ will be defined. Also, using $A_{0}$ enables us to evaluate $y_{1}(x)$. The determination of $y_{0}(x)$ and $y_{1}(x)$ leads to the determination of $A_{1}$ that will allow us to determine $y_{2}(x)$, and so on. The recursive relation is given by

$$
\begin{aligned}
y_{0}(x) & =\mathcal{L}^{-1}\left\{\frac{\alpha}{s}+\frac{\beta}{s^{2}}+\frac{1}{s^{2}} \mathcal{L}\{f(x)\}\right\}, \\
y_{k+1}(x) & =\mathcal{L}^{-1}\left\{\frac{1}{s^{2}} \mathcal{L}\left\{\int_{a}^{x} \Psi_{1}(x, t)\left(\Delta_{1}\left(y_{k}(t)\right)+A_{k}\right) d t+\int_{a}^{b} \Psi_{2}(x, t)\left(\Delta_{2}\left(y_{k}(t)\right)+B_{k}\right) d t\right\}\right\} .
\end{aligned}
$$

\section{Numerical Example}

In this section, we proposed a numerical solution for nonlinear integro-differential equations by using the LDADM see numerical results in Table 1 and Figs. 1-2.

Example 3.1. Consider the following nonlinear integro-differential equation:

$$
y^{\prime \prime}(x)=\frac{1}{2} e^{x}+\frac{1}{2} \int_{0}^{x} e^{x-2 t} y^{2}(t) d t
$$

with the following initial conditions

$$
y(0)=y^{\prime}(0)=1
$$

Therefore the exact solution is $y(x)=e^{x}$. 
Solution: Taking the Laplace transform of both sides of the Eq. (3.1)

$$
\mathcal{L}\left\{y^{\prime \prime}(x)\right\}=\mathcal{L}\left\{\frac{1}{2} e^{x}\right\}+\mathcal{L}\left\{\frac{1}{2} \int_{0}^{x} e^{x-2 t} y^{2}(t) d t\right\} .
$$

From (2.1)

$$
s^{2} \mathcal{L}\{y(x)\}-s y(0)-y^{\prime}(0)=\mathcal{L}\left\{\frac{1}{2} e^{x}\right\}+\mathcal{L}\left\{\frac{1}{2} \int_{0}^{x} e^{x-2 t} y^{2}(t) d t\right\}
$$

by (3.2)

$$
\mathcal{L}\{y(x)\}=\frac{1}{s}+\frac{1}{s^{2}}+\frac{1}{2 s^{2}(s-1)}+\frac{1}{2 s^{2}} \mathcal{L}\left\{\int_{0}^{x} e^{x-2 t} y^{2}(t) d t\right\},
$$

the recursive relation is given by

$$
\begin{aligned}
y_{0}(x) & =\mathcal{L}^{-1}\left\{\frac{1}{s}+\frac{1}{s^{2}}+\frac{1}{2 s^{2}(s-1)}\right\} \\
y_{k+1}(x) & =\mathcal{L}^{-1}\left\{\frac{1}{2 s^{2}} \mathcal{L}\left\{\int_{0}^{x} e^{x-2 t} A_{k} d t\right\}\right\}, k \geqslant 0 .
\end{aligned}
$$

Table 1: Numerical Results of the Example 3.1.

\begin{tabular}{lccccc}
\hline $\mathrm{x}$ & Exact & ADM & LDADM & Error $_{\text {ADM }}$ & Error $_{\text {LDADM }}$ \\
\hline 0.0 & 1.00000000 & 1.00000000 & 1.00000000 & 0.000000000 & 0.000000000 \\
0.2 & 1.22140276 & 1.22010210 & 1.22140206 & $1.30066 \times 10^{-3}$ & $0.700 \times 10^{-6}$ \\
0.4 & 1.49182470 & 1.45262489 & 1.49182168 & $3.919981 \times 10^{-2}$ & $0.302 \times 10^{-5}$ \\
0.6 & 1.82211880 & 1.81302140 & 1.82211150 & $9.0974 \times 10^{-3}$ & $0.730 \times 10^{-5}$ \\
0.8 & 2.22554093 & 2.22032852 & 2.22552695 & $5.21241 \times 10^{-3}$ & $1.398 \times 10^{-5}$ \\
1.0 & 2.71828183 & 2.71223606 & 2.71825824 & $6.04577 \times 10^{-3}$ & $2.359 \times 10^{-5}$ \\
\hline
\end{tabular}

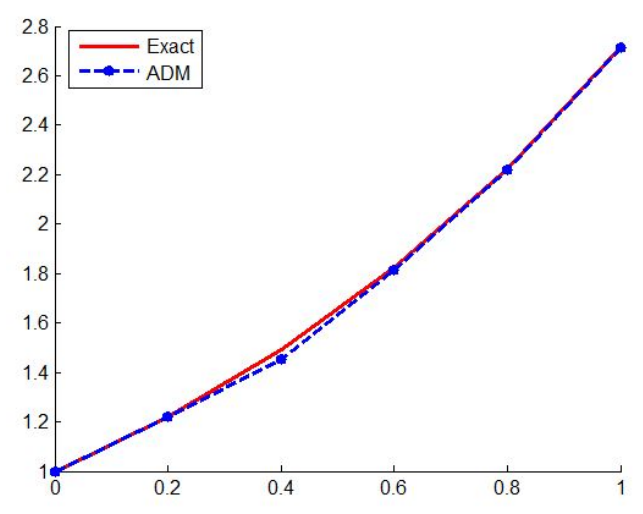

Figure 1: Numerical Results of the Example 3.1.

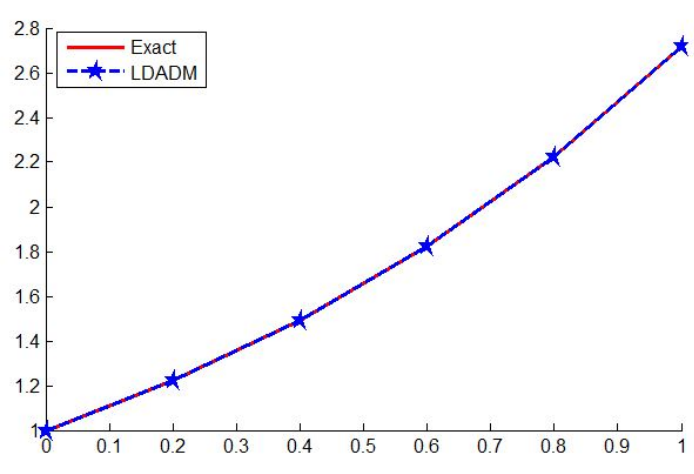

Figure 2: Numerical Results of the Example 3.1.

\section{Conclusions}

In this paper, new modification of the Adomian decomposition method inspired by the property of discretization is proposed. We developed a new Laplace Discrete Adomian decomposition method in which has been successfully applied to finding efficient numerical solutions of nonlinear VolterraFredholm integro-differential equations. The LDADM gives approximate solutions iteratively with less number of computational steps comparison with ADM (see Table 1, Fig. 1 and Fig. 2). The results reveal that the proposed method is simple to execute and effective. 


\section{References}

[1] O. Abu Arqub, M. Al-Smadi, Numerical algorithm for solving two-point, second-order periodic boundary value problems for mixed integro-differential equations, Appl. Math. Comput., 243 (2014), 911-922. 1

[2] O. Abu Arqub, M. Al-Smadi, N. Shawagfeh, Solving Fredholm integro-differential equations using reproducing kernel Hilbert space method, Appl. Math. Comput., 219 (2013), 8938-8948. 1

[3] O. Abu Arqub, B. Maayah, Solutions of Bagley-Torvik and Painleve equations of fractional order using iterative reproducing kernel algorithm, Neural Comput. Appl., 29 (2018), 1465-1479. 1

[4] A. Akyüz, M. Sezer, A Chebyshev collocation method for the solution of linear integro-differential equations, Int. J. Comput. Math., 72 (1999), 491-507. 1

[5] S. Alkan, V. F. Hatipoglu, Approximate solutions of Volterra-Fredholm integro-differential equations of fractional order, Tbilisi Math. J., 10 (2017), 1-13. 1

[6] M. Al-Mazmumy, H. Al-Malki, Some modifications of adomian decomposition methods for nonlinear partial differential equations, Int. J. Res. Agricul. Sci., 23 (2015), 164-173. 1

[7] H. O. Bakodah, M. Al-Mazmumy, S. O. Almuhalbedi, An efficient modification of the Adomian decomposition method for solving integro-differential equations, Math. Sci. Lett., 6 (2017), 15-21. 1, 2

[8] L. M. Delves, J. L. Mohamed, Computational Methods for Integral Equations, Cambridge University Press, Cambridge, (1985). 1

[9] W. H. Enright, M. Hu, Continuous Runge-Kutta methods for neutral Volterra integro-differential equations with delay, Appl. Numer. Math., 24 (1997), 175-190. 1

[10] A. A. Hamoud, M. S. Bani Issa, K. P. Ghadle, Existence and uniqueness results for nonlinear Volterra-Fredholm integro differential equations, Nonlinear Funct. Anal. Appl., 23 (2018), 797-805. 1

[11] A. A. Hamoud, L. A. Dawood, K. P. Ghadle, S. M. Atshan, Usage of the modified variational iteration technique for solving Fredholm integro-differential equations, Int. J. Mech. Prod. Eng. Res. Develop., 9 (2019), 895-902. 1

[12] A. A. Hamoud, K. P. Ghadle, The combined modified Laplace with Adomian decomposition method for solving the nonlinear Volterra-Fredholm integro-differential equations, J. Korean Soc. Ind. Appl. Math., 21 (2017), 17-28. 1

[13] A. A. Hamoud, K. P. Ghadle, The reliable modified of Laplace Adomian decomposition method to solve nonlinear interval Volterra-Fredholm integral equations, Korean J. Math., 25 (2017), 323-334. 1

[14] A. A. Hamoud, K. P. Ghadle, Existence and uniqueness of solutions for fractional mixed Volterra-Fredholm integrodifferential equations, Indian J. Math., 60 (2018), 375-395. 1

[15] A. A. Hamoud, K. P. Ghadle, Homotopy analysis method for the first order fuzzy Volterra-Fredholm integro-differential equations, Indonesian J. Ele. Eng. Comput. Sci., 11 (2018), 857-867. 1

[16] A. A. Hamoud, K. P. Ghadle, Modified Adomian decomposition method for solving fuzzy Volterra-Fredholm integral equations, J. Indian Math. Soc., 85 (2018), 52-69. 1

[17] A. A. Hamoud, K. P. Ghadle, Modified Laplace decomposition method for fractional Volterra-Fredholm integro-differential equations, J. Math. Model., 6 (2018), 91-104. 1, 2

[18] A. A. Hamoud, K. P. Ghadle, The approximate solutions of fractional Volterra-Fredholm integro-differential equations by using analytical techniques, Probl. Anal. Issues Anal., 7 (2018), 41-58. 1

[19] A. A. Hamoud, K. P. Ghadle, Usage of the homotopy analysis method for solving fractional Volterra-Fredholm integrodifferential equation of the second kind, Tamkang J. Math., 49 (2018), 301-315. 1

[20] A. A. Hamoud, K. P. Ghadle, Some new existence, uniqueness and convergence results for fractional Volterra-Fredholm integro-differential equations, J. Appl. Comput. Mech., 5 (2019), 58-69. 1

[21] A. A. Hamoud, K. P. Ghadle, S. M. Atshan, The approximate solutions of fractional integro-differential equations by using modified Adomian decomposition method, Khayyam J. Math., 5 (2019), 21-39. 1

[22] A. A. Hamoud, K. P. Ghadle, M. S. Bani Issa, Giniswamy, Existence and uniqueness theorems for fractional VolterraFredholm integro-differential equations, Int. J. Appl. Math., 31 (2018), 333-348.

[23] A. A. Hamoud, K. P. Ghadle, P. A. Pathade, An existence and convergence results for Caputo fractional Volterra integrodifferential equations, Jordan J. Math. Stat., 12 (2019), 307-327. 1

[24] A. A. Hamoud, K. H. Hussain, K. P. Ghadle, The reliable modified Laplace Adomian decomposition method to solve fractional Volterra-Fredholm integro-differential equations, Dyn. Contin. Discrete Impuls. Syst. Ser. B Appl. Algorithms, 26 (2019), 171-184. 1

[25] A. A. Hamoud, K. H. Hussain, N. M. Mohammed, K. P. Ghadle, Solving Fredholm integro-differential equations by using numerical techniques, Nonlinear Funct. Anal. Appl., 24 (2019), 533-542.

[26] A. A. Hamoud, N. M. Mohammed, K. P. Ghadle, A study of some effective techniques for solving Volterra-Fredholm integral equations, Dyn. Contin. Discrete Impuls. Syst. Ser. A Math. Anal., 26 (2019), 389-406.

[27] K. H. Hussain, A. A. Hamoud, N. M. Mohammed, Some new uniqueness results for fractional integro-differential equations, Nonlinear Funct. Anal. Appl., 24 (2019), 827-836. 1

[28] A. Karamete, M. Sezer, A Taylor collocation method for the solution of linear integro-differential equations, Int. J. Comput. Math., 79 (2002), 987-1000. 1

[29] S. A. Khuri, A Laplace decomposition algorithm applied to a class of nonlinear differential equations, J. Appl. Math., 1 (2001), 141-155. 1 
[30] O. Kiymaz, An Algorithm for solving initial value problems using Laplace Adomian decomposition method, Appl. Math. Sci. (Ruse), 3 (2009), 1453-1459. 1

[31] K. Maleknejad, F. Mirzaee, S. Abbasbandy, Solving linear integro-differential equations system by using rationalized Haar functions method, Appl. Math. Comput., 155 (2004), 317-328. 1

[32] K. Maleknejad, M. Tavassoli Kajani, Solving linear integro-differential equation system by Galerkin methods with hybrid functions, Appl. Math. Comput., 159 (2004), 603-612. 1

[33] D. Nazari, S. Shahmorad, Application of the fractional differential transform method to fractional-order integro-differential equations with nonlocal boundary conditions, J. Comput. Appl. Math., 234 (2010), 883-891. 1

[34] A.-M. Wazwaz, Linear and Nonlinear Integral Equations Methods and Applications, Springer, Heidelberg, (2011). 1, 2 